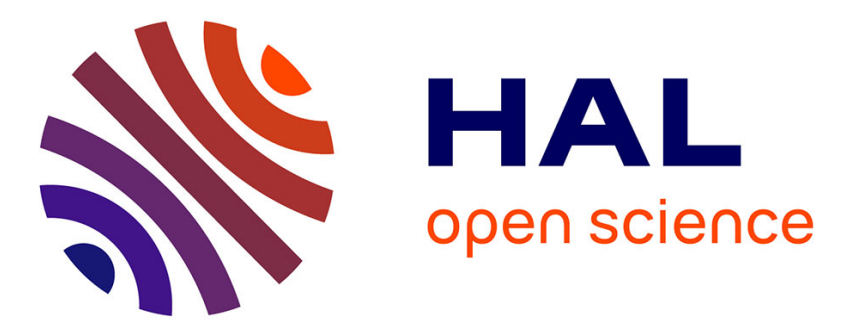

\title{
THE REACTIVITY AND MOLECULAR SIZE OF FILM PRECURSORS DURING CHEMICAL VAPOR DEPOSITION OF WSix
}

\author{
Y. Shimogaki, T. Saito, F. Tadokoro, H. Komiyama
}

\section{- To cite this version:}

Y. Shimogaki, T. Saito, F. Tadokoro, H. Komiyama. THE REACTIVITY AND MOLECULAR SIZE OF FILM PRECURSORS DURING CHEMICAL VAPOR DEPOSITION OF WSix. Journal de Physique IV Proceedings, 1991, 02 (C2), pp.C2-95-C2-102. 10.1051/jp4:1991211 • jpa-00249788

\section{HAL Id: jpa-00249788 https://hal.science/jpa-00249788}

Submitted on 1 Jan 1991

HAL is a multi-disciplinary open access archive for the deposit and dissemination of scientific research documents, whether they are published or not. The documents may come from teaching and research institutions in France or abroad, or from public or private research centers.
L'archive ouverte pluridisciplinaire HAL, est destinée au dépôt et à la diffusion de documents scientifiques de niveau recherche, publiés ou non, émanant des établissements d'enseignement et de recherche français ou étrangers, des laboratoires publics ou privés. 


\title{
THE REACTIVITY AND MOLECULAR SIZE OF FILM PRECURSORS DURING CHEMICAL VAPOR DEPOSITION OF WS $i_{x}$
}

\author{
Y. SHIMOGAKI, T. SAITO, F. TADOKORO and H. KOMIYAMA \\ Department of Chemical Engineering, The University of \\ Tokyo, 7-3-1 Hongo, Bunkyo-ku, Tokyo 113, Japan
}

\begin{abstract}
A kinetic study of chemical vapor deposition of tungsten silicide films was made, focusing on the reactivity and molecular size of film precursors. Tungsten silicide (WSi) films were deposited by low pressure $\mathrm{CVD}$ from $\mathrm{SiH}_{4}$ and $\mathrm{WF}_{6}$. The molecular size of the film precursor was calculated to fit to the diffusion coefficient obtained from the deposition rate profile in a tubular reactor. Typically the size was $5 \sim 6 \AA$, which is close to the size of the $\mathrm{WF}_{6}$ molecule. The sticking probability of the film precursor was also examined by observing step coverage in a micron size trench. The sticking probability was about 0.5 at $270 \sim 360^{\circ} \mathrm{C}$ and dependent only slightly on temperature. The partial pressure ratio of $\mathrm{SiH}_{4}$ to $\mathrm{WF}_{6}$ was varied from 5 to 100 , but the sticking probability did not change and the step coverage remained poor Some modifications of reaction system would be required to improve the step coverage.
\end{abstract}

\section{1.- Introduction}

Refractory metal silicides are appropriate materials for low resistive electrodes. Several metal silicides, such as $\mathrm{MoSi}_{x}$, TiSi $i_{x}$, WSi $i_{x}$, have been examined and tungsten silicide (WSi $)$ has been found to be a promising material for VLSI technology. ${ }^{1}$ The superior thermal stability and oxidation properties of $\mathrm{WSi}_{x}$ have enabled it to be substituted easily for polysilicon which had been used as gate electrode. $\mathrm{WSi}_{\mathrm{x}}$ films are now extensively used in VLSI, for example in $4 \mathrm{Mb}$ dynamic ranciom access memories (DRAM), and contribute to shortening the access time of the device.

Chemical vapor deposition (CVD) process is widely employed to deposit $\mathrm{WSi}_{x}$ films and $\mathrm{WF}_{6} / \mathrm{SiH}_{4}$ or $\mathrm{WF}_{6} / \mathrm{SiH}_{2} \mathrm{Cl}_{2}$ are used as source gases. By using $\mathrm{SiH}_{4}$ for the $\mathrm{Si}$ source, the deposition can be carried out at as low a temperature as $300 \sim 400^{\circ} \mathrm{C}$. However, the poor step coverage quality and residual fluorine in the deposited film are the major drawbacks of this process. Kinetic information of the deposition chemistry is required to improve these problems. ${ }^{2}$ Tungsten films can also be deposited from this reaction mixture by decreasing the ratio of $\mathrm{SiH}_{4}$ to $\mathrm{WF}_{6}$ below unity. A kinetic investigation of $\mathrm{WSi}_{\mathrm{x}}-\mathrm{CVD}$ processes will provide useful information for $\mathrm{W}$-deposition processes. Brors et al. ${ }^{1}$ reported that the mixture of $\mathrm{SiH}_{4}$ and $\mathrm{WF}_{6}$ can easily react in the gas phase when the concentration is high. This phenomenon suggests the existence of intermediate species during the film deposition process. In the present work, the molecular size of film forming species was predicted by measuring the deposition rate profile in the reactor. The reactivity of the film forming species was also examined by using micronsize trenches. 


\section{2.- Experimental}

The experimental setup employed in the present work is schematically depicted in Fig.1. Pure $\mathrm{WF}_{6}$ and $\mathrm{SiH}_{4}$ were used as reactant gas. The cylinder of $\mathrm{WF}_{6}$ was heated up to $40^{\circ} \mathrm{C}$ to get enough vapor pressure. Ar was also used as an inert gas to control the total pressure without changing the partial pressures of each reacting agent. The flow rates of each gas were regulated by thermal mass flow controllers (TMFC) to give a desired partial pressure and residence time in the reactor. The total flow rate examined in this work ranged from 50 to 300 standard cubic centimeters per minute (sccm). The total pressure of the reaction system was monitored by a capacitance manometer (MKS, Baratron Type 122A) and it was kept constant during a run by controlling the butterfly valve located down stream of the reactor. The typical total pressure was 0.4 Torr in this study. Under these conditions, the gaseous flow in the reactor was laminar, with Reynolds number in the range of 7 45. The reactor was composed of a glass tube that had an outer diameter of $13 \mathrm{~mm}$ and inner diameter of $11 \mathrm{~mm}$. Short glass rings, whose length, outer diameter, and inner diameter were $10 \mathrm{~mm}, 11 \mathrm{~mm}$ and $9 \mathrm{~mm}$, respectively, were inserted into the reactor and used as substrates to obtain deposition rate profiles. An inductively coupled plasma (ICP) technique was employed to measure the deposited amount of $\mathrm{W}$ on the inner wall of glass ring substrates. A silicon wafer that has micron-size trench, fabricated by normal lithographic process, was also used as substrate to investigate the step coverage quality of the deposited film by scanning electron microscope (SEM). The reactor was heated by a resistive furnace. The length of the furnace was $20 \mathrm{~cm}$. The temperature of the furnace was measured by a thermocouple, which was attached on the outer wall of the reactor, and controlled by a PID-temperature controller. A typical temperature profile of the inner wall of the reactor is shown in Fig.2. The temperature becomes close to the desired value at $3 \mathrm{~cm}$ from the inlet and a uniform temperature profile could be obtained after that point. The silicon wafer, which was used to examine the step coverage, was located in this uniform temperature zone.
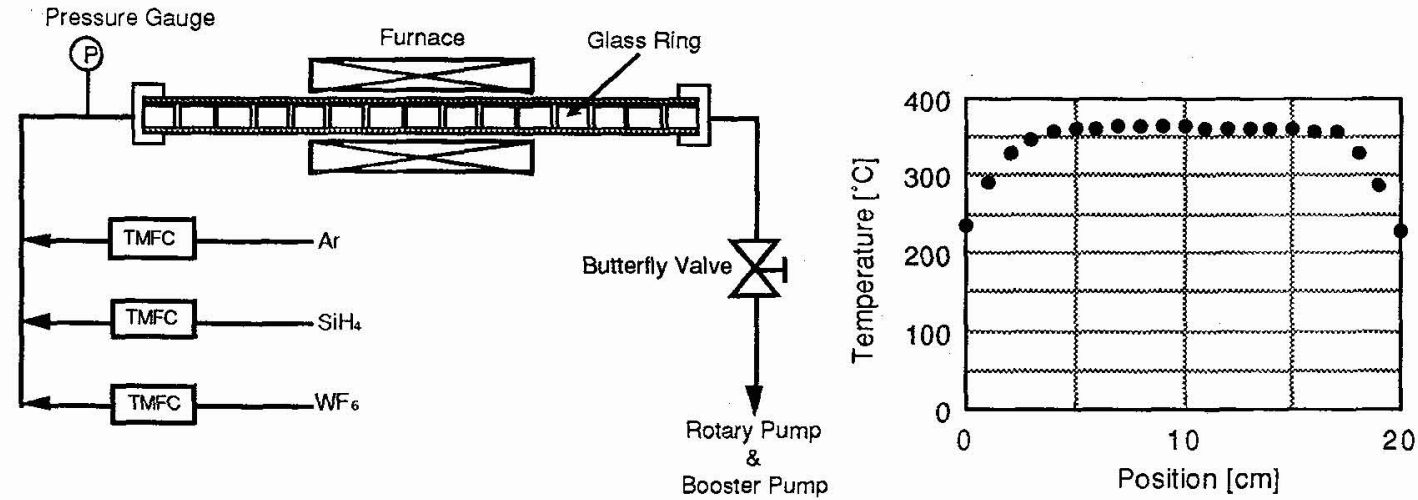

Fig. 1 The experimental setup.

Fig. 2 The temperature profile in the reactor.

\section{3.- Results and Discussions}

\subsection{Deposition Rate Profile}

A deposition rate profile in the tubular reactor was investigated to obtain the overall reaction rate constant. If the film deposition is a first order process, the longitudinal concentration profile in a tubular reactor can be expressed as 


$$
\frac{C}{C_{0}}=\exp \left(-k \frac{4 x}{d u}\right)
$$

where $u$ is the linear flow velocity of the gas, $d$ is the diameter of the reactor, $x$ is the length from the reactor inlet, and $k$ is the over all first-order rate constant with a dimension of $m / s$. The rate constant, $k$, can be calculated from the deposition rate profile, because the deposition rate is proportional to the concentration. If the surface reaction rate of the film forming species is much faster than the mass transport rate, the rate constant $k$ is equal to the mass transport coefficient, $k_{d}$. It can be described as follows.

$$
k_{d}=\operatorname{Sh} \frac{D}{d}
$$

Here $S h$ is Sherwood number and $D$ is the diffusion coefficient of film forming species. Sherwood number can be theoretically given by infinite series equation when the gaseous flow in a tubular reactor is laminar. ${ }^{3}$ The local Sherwood number is given as follows.

$$
S h=\frac{\sum_{n=0}^{\infty} G_{n} \exp \frac{-\beta_{n}^{2}(2 x / d)}{P e}}{2 \sum_{n=0}^{\infty} \frac{G_{n}}{\beta_{n}^{2}} \exp \frac{-\beta_{n}^{2}(2 x / d)}{P e}}
$$

Here $\beta_{n}$ is the eigen value and $G_{n}$ is the corresponding eigen function. $P e$ is the Peclet number (=du/D). According to the equation, $S h$ is infinite at the inlet of the reactor but quickly becomes small value at the down stream of the reactor. In particular, for $(2 x / d) / P e>0.25$, Sh is constant at 3.657. This criterion can be achieved at around $2 \mathrm{~cm}$ from the inlet within our experimental conditions. Therefore, the deposition rate profile is changed by changing the total pressure under the transport limited regime, because $D$ is in inverse proportion to the total pressure. On the other hand, if the transport rate is high enough, the rate constant $k$ is equal to the surface reaction rate constant $k_{s}$ and will not show any pressure dependence.

Three experimental runs were performed at the same temperature of $360^{\circ} \mathrm{C}$. The partial pressures of $\mathrm{SiH}_{4}$ and $\mathrm{WF}_{6}$ were also kept constant at 396 mTorr and $4 \mathrm{mTorr}$, respectively. The total pressure was changed by adding suitable amounts of $\mathrm{Ar}$ as an inert gas and the linear velocity of the gas was kept constant for each experiment. The deposited films on the glass ring substrates were dissolved by a mixture of $\mathrm{HF}$ and $\mathrm{HNO}_{3}$. The concentration of $\mathrm{W}$ in the solution was measured by ICP, and the longitudinal W-deposition rate profile in the reactor was obtained. Figure 3 shows the results.

The deposition rate was plotted in a logarithmic form and a good linear relation ship was obtained, indicating that the film forming process obeys a first-order rate law. The rate constant calculated from the slope decreased with increasing total pressure. This phenomenon suggests that the process was controlled by the mass transport rate. The diffusion coefficient can be obtained from the rate constant by using equation (2). The binary diffusion coefficient can be estimated by well-known "Chapman-Enskog" equation, which is given by

$$
\begin{aligned}
& D_{A B}=1.8825 \times 10^{-22} \frac{T^{3 / 2}\left[\left(M_{A}+M_{B}\right) / M_{A} M_{B}\right]^{1 / 2}}{P \sigma_{A B}^{2} \Omega_{D}} \\
& \sigma_{A B}=\frac{1}{2}\left(\sigma_{A}+\sigma_{B}\right)
\end{aligned}
$$

Here the subscripts of $A$ and $B$ mean the diffusing species. A refers to the ambient gas and $B$ represents the film forming species. $M$ and $\sigma$ represents the molecular weight and the molecular size of each 
species, respectively, and $P$ is the total pressure. $\Omega_{D}$ is a collision cross section and equal to unity. The molecular weight of film forming spectes $\left(M_{B}\right)$ is much larger than that of the ambient gas $\left(M_{\mathcal{A}}\right)$, because it should contain $W$ atoms. Then we can simplify the equation (4) as follows.

$$
D_{A B}=1.8825 \times 10^{-22} \frac{T^{3 / 2} M_{A}^{-1 / 2}}{P \sigma_{A B} \Omega^{2}}
$$

If the ambient gas is a mixture, $\mathrm{SiH}_{4}$ and $\mathrm{Ar}$ in the present case, the overall diffusion coefficient $\mathrm{D}_{\mathrm{ov}}$ can be predicted from the following equation. ${ }^{4}$ This equation is valid when the concentration of intermediate species is comparatively smaller than the ambient gases.

$$
\frac{1}{D_{\text {ov }}}=\frac{1}{D_{\text {SitA-B }}}+\frac{1}{D_{\text {Ar-B }}}
$$

$D_{\text {SiH4-B }}$ and $D_{A r-B}$ are the binary diffusion coefficient of film forming species in each ambient gas, respectively. These coefficients are given by the equation (6) and the partial pressures of $\mathrm{SiH}_{4}$ and Ar should be used instead of total pressure. Thus the molecular size of the film precursors can be predicted from these equations. The appropriate sizes for the experimental results are summarized in Table. 1. Another series of experiments was carried out to examine the effects of temperature and concentration. The calculated results are also shown in Table.1.

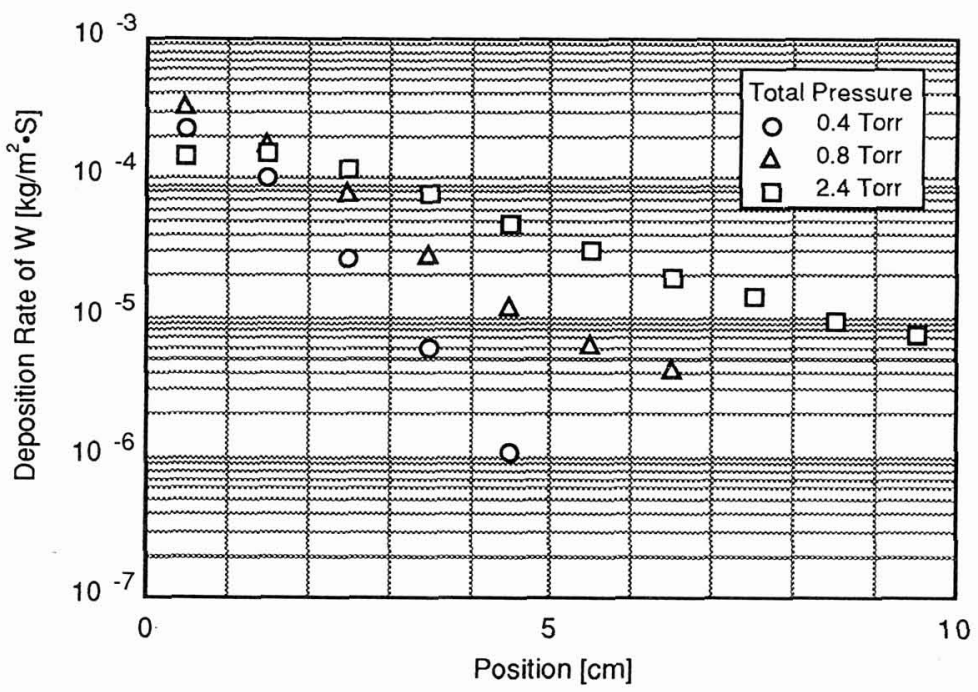

Fig. 3 The deposition rate profile in the tubular reactor.

Temperature : $360^{\circ} \mathrm{C}$

Partial Pressure of $\mathrm{WF}_{6}: 4 \mathrm{mTorr}$

Partial Pressure of $\mathrm{SiH}_{4}: 396 \mathrm{mT}$ Torr

* The total pressure was controlled by Ar and the linear velocity of the gas was kept constant.

The molecular size of film forming species were around $5 \sim 6 \AA$ at $360^{\circ} \mathrm{C}$ and did not show any tendency to be changed by the total pressure or partial pressure. There is no information on the molecular size of $W$ containing species, but the sizes of $\mathrm{UF}_{6}$ and $\mathrm{SF}_{6}$ are known to be 5.97 and $5.13 \AA$, respectively. The calculated value is quite close to the expected size of $\mathrm{WF}_{6}$ molecule and so $\mathrm{WF}_{6}$ itself may be the film growth species. However, with decreasing temperature, the molecular size increases to around $8 \AA$ at 
$240^{\circ} \mathrm{C}$, which suggests that some gas phase reactions were contributing to the film growth processes. At low temperature, the gas phase reaction is slow and the intermediate species might remain in the form like as $\mathrm{WF}_{\mathrm{x}}\left(\mathrm{SiH}_{3}\right)_{6-\mathrm{x}}$. But, at high temperature the reaction proceeds and the intermediate species become a final structure like WSi $\mathbf{W}_{\mathbf{x}}$. Although the chemical nature of the film precursors cannot be identified from the present information alone, it could help future work on the identification of intermediate species by some monitoring methods.

Table. 1 The molecular size of film precursors.

\begin{tabular}{|c|c|c|c|c|c|}
\hline $\begin{array}{c}\text { Temp. } \\
{\left[{ }^{\circ} \mathrm{C}\right]}\end{array}$ & $\begin{array}{c}\text { PWF6 } \\
{[\mathrm{m} \text { Torr] }]}\end{array}$ & $\begin{array}{c}\text { PSiH4 } \\
{[\mathrm{m} \text { Torr] }}\end{array}$ & $\begin{array}{c}\text { PAr } \\
{[\text { Torr] }}\end{array}$ & $\begin{array}{c}\text { Total Pressure } \\
{[\text { Torr] }]}\end{array}$ & $\begin{array}{c}\text { Molecular Siza } \\
{[\AA]}\end{array}$ \\
\hline 360 & 4 & 396 & 0 & 0.4 & 5.4 \\
360 & 4 & 396 & 0.4 & 0.8 & 5.2 \\
360 & 4 & 396 & 2 & 2.4 & 3.7 \\
\hline 360 & 4 & 396 & 0 & 0.4 & 5.4 \\
360 & 8 & 792 & 0 & 0.8 & 4.3 \\
360 & 16 & 1584 & 0 & 1.6 & 5.9 \\
\hline 240 & 4 & 396 & 0 & 0.4 & 7.6 \\
300 & 4 & 396 & 0 & 0.4 & 6.4 \\
360 & 4 & 396 & 0 & 0.4 & 5.4 \\
\hline
\end{tabular}

\subsection{Step Coverage}

Next, the quality of step coveragewithin a micron-size trench was investigated to obtain the sticking probabilities of the film precursors. The micron-size trenches were fabricated on a silicon wafer by normal lithographic procedures employed in LSI technology. In this paper, we define the step coverage as the ratio of film thickness at the bottom of the trench to the film thickness at the surface of the Si wafer $\left(t_{B} / t_{S}\right.$, see Fig.4).

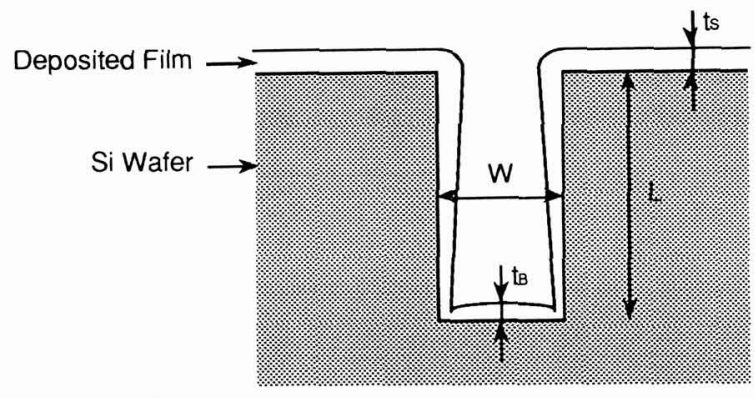

Fig. 4 The schematic representation of micron-size trench.

By assuming a one dimensional hypothesis, the step coverage in the trench with width of $W$ and depth of $L$ can be described as

$$
\begin{aligned}
& \frac{t_{B}}{t s}=\frac{1}{\cosh \phi+\frac{\phi}{2} \frac{L}{W} \sinh \phi}, \\
& \phi=\frac{L}{W} \sqrt{\frac{3 \eta}{2}},
\end{aligned}
$$

where $\eta$ is the sticking probability of film forming species. The step coverage is governed by the stick- 
ing probability and aspect ratio, defined as the ratio of depth to width of the trench. Figure 5 shows the relation between sticking probability and step coverage. $\eta$ should be lower than 0.01 to get conformal step coverage.

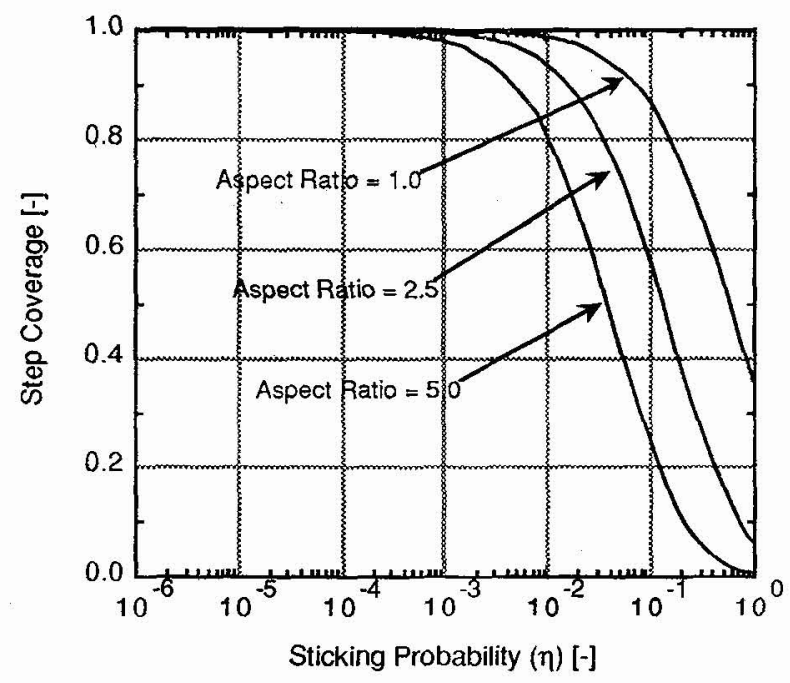

Fig. 5 The relation between step coverage and sticking probability.

A silicon wafer with a micron-size trench was cut out with a size of $6 \mathrm{~mm} \times 15 \mathrm{~mm}$ and inserted into the uniform temperature zone shown in Fig.2. The depth of the trench was around $3.0 \mu \mathrm{m}$ and the width was ranged from 0.8 to $3.0 \mu \mathrm{m}$. The deposition was carried out with constant partial pressures of $\mathrm{WF}_{6}$ and $\mathrm{SiH}_{4}$ at $4 \mathrm{~m}$ Torr and $396 \mathrm{mTorr}$, respectively, and the effect of temperature on the step coverage quality was investigated. After the deposition, the fractured surface of the silicon wafer was observed by SEM. The typical examples of the step coverage are shown in Fig.6. The sticking probabilities were calculated from these photographs.
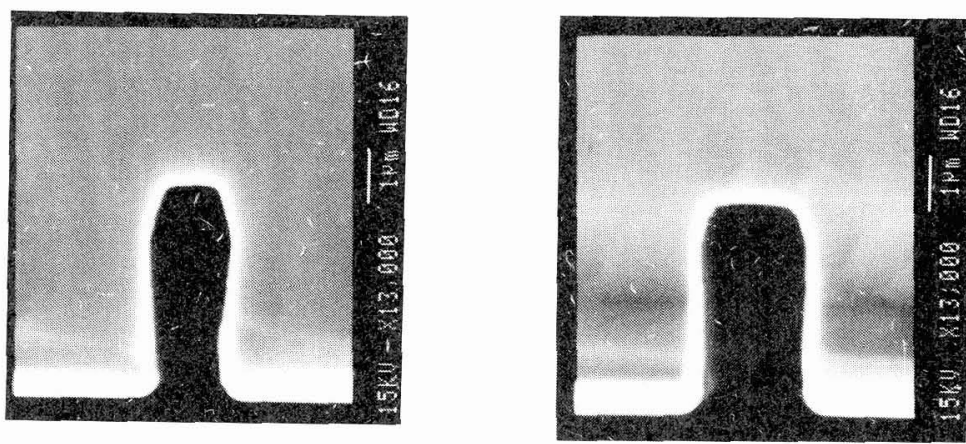

Fig. 6 The SEM photographs of step coverage.

Temperature : $360^{\circ} \mathrm{C}$

Partial Pressure of $\mathrm{WF}_{6}: 4 \mathrm{mT}$ Trr

Partial Pressure of $\mathrm{SiH}_{4}: 396 \mathrm{mT}$ Torr

Total Pressure : 1.0Torr

The relation between calculated sticking probabilities and the deposition temperature is depicted in Fig.7. The high value of $\eta$ strongly supports our experimental results that the deposition was con- 
trolled by mass transport rate. The temperature dependency of the sticking probability is almost negligible and the step coverage cannot be modified by controlling the temperature. However, the reaction does not occur at room temperature, which means the sticking probability of source gas is negligibly small at room temperature. Therefore, it is suggested that some active species is formed by a gas phase reaction and the poor step coverage resulted from this intermediate species, i.e., film precursors, which have high sticking probability of 0.5 . The intermediate species may be a kind of radical, because it has a high sticking probability and its molecular size is close to the size of source gas.

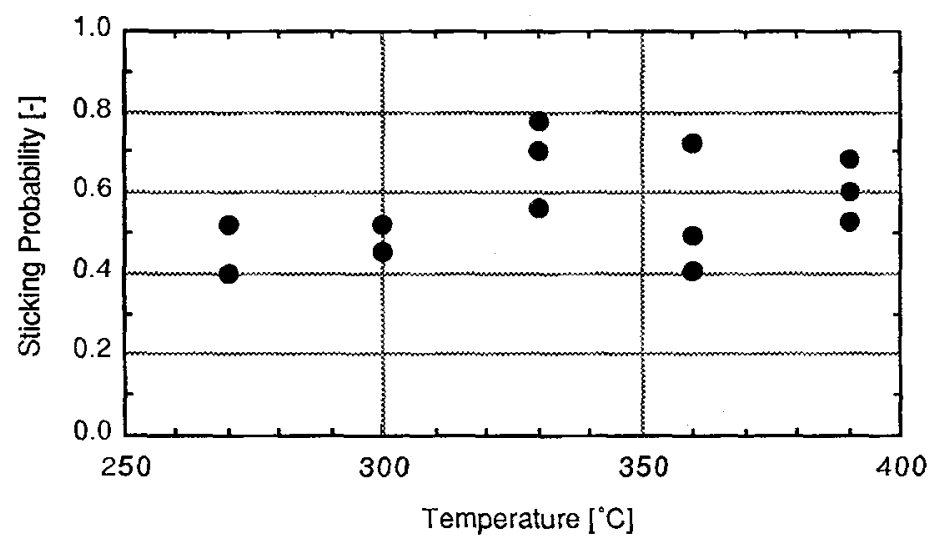

Fig. 7 The temperature dependency of the sticking probabilities.

Partial Pressure of $\mathrm{WF}_{6}: 4 \mathrm{mTorr}$

Partial Pressure of $\mathrm{SiH}_{4}: 396 \mathrm{mT}$ Trr

Total Pressure : 1.OTorr

Figure 8 shows the effect of $\mathrm{SiH}_{4}$ to $\mathrm{WF}_{6}$ ratio on the sticking probability. $\eta$ was also high at around 0.5 and did not show any significant change within the experimental conditions $\left[\mathrm{SiH}_{4} / \mathrm{WF}_{6}=\right.$ $5 \sim 100$ ). It is known that uniform deposition can be easily obtained in W-deposition by decreasing $\mathrm{SiH}_{4} / \mathrm{WF}_{6}$ below unity. The sticking probability should be lower than 0.01 . The drastic change of step coverage can be explained either by the change of surface conditions or by the modification of gas phase intermediate species. Further work, such as in situmeasurement of the gas phase species, is required to clarify these problems.

The active intermediate species is often formed by gas phase reactions in many CVD processes. The authors previously investigated the reactivity and molecular size of the film forming species during the chemical vapor deposition of $\mathrm{AlN}^{5} \mathrm{CuO}_{x}{ }^{6}$ and $\mathrm{SiO}_{2}{ }^{7}$ films. The active species were formed in the gas phase in each process and contributed to the film growth. The molecular sizes of the active species obtained from the growth rate profiles were around $10 \AA$ in the case of $\mathrm{AlN}$ and $\mathrm{CuO}_{\mathrm{x}}$. The clusters should be the major film growth species in these processes. In the case of $\mathrm{SiO}_{2}$ deposition from TEOS, the size of the intermediate species was close to that of the source gas. ${ }^{8}$ The sticking probability was almost unity and the quality of step coverage was very poor. A chemical modification of the reaction system is required to improve the film uniformity in micron-size trenches. We are trying to investigate the effect of adding $\mathrm{H}_{2} \mathrm{O}$ or $\mathrm{NH}_{3}$ in the thermal decomposition of TEOS to produce $\mathrm{SiO}_{2}$ films. ${ }^{7}$ If the chemical nature of the active species can be modified, the step coverage quality will become better. A similar approach can be taken for the tungsten silicide deposition process. Hydrogen is a hopeful candidate to improve the step coverage, because the deposition of $\mathrm{W}$ films from a $\mathrm{WF}_{6} / \mathrm{H}_{2}$ mixture shows better step coverage quality. 


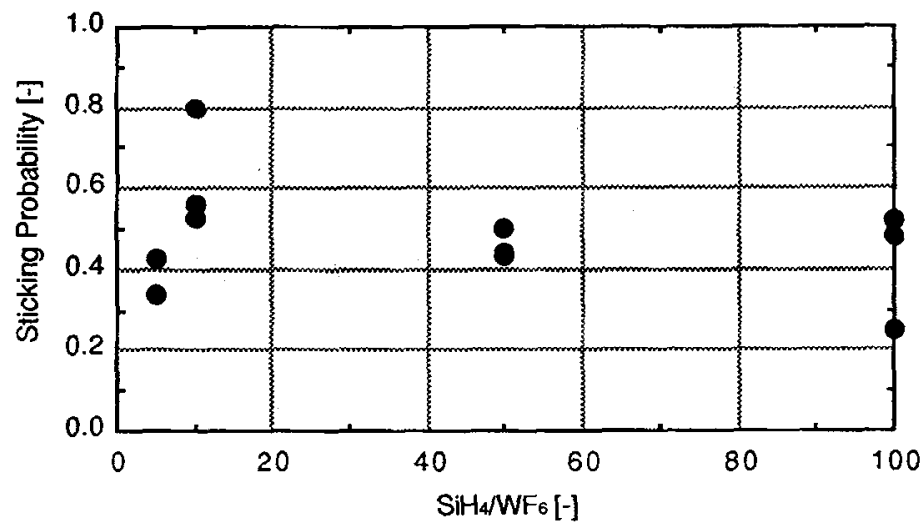

Fig. 8 The effect of $\mathrm{SiH}_{4} / \mathrm{WF}_{6}$ on the sticking probability.

Temperature : $360^{\circ} \mathrm{C}$

Partial Pressure of $\mathrm{WF}_{6}: 4 \mathrm{mT}$ Torr

Total Pressure : 1.0Torr

\section{4.- Conclusion}

$W_{S i} i_{x}$ films were deposited by low pressure CVD. The molecular size of the film precursor was predicted to be $5 \sim 6 \AA$ at a growth temerature of $360^{\circ} \mathrm{C}$. This size is close to the molecular size of $\mathrm{WF}_{6}$, but the size increased with decreasing the temperature. The sticking probability of this precursor was determined by using micron-size trench to be high at around 0.5 . This large sticking probability and the molecular size dependency on temperature suggest the formation of active species by a gas phase reaction. A chemically active intermediate species having a molecular stze similar to that of $\mathrm{WF}_{6}$ formed in the gas phase is a key species in this CVD system. Work is now under way to identify the intermediate species by infrared (IR) spectroscopy or mass spectroscopy.

\section{References}

/1/ D.L. Brors, J.A. Fair, K.A. Monnig, K.C. Saraswat, Proc. 9 th Int. Conf. CVD, p.275, (1984).

/2/ Y. Shioya, S. Kawamura, I. Kobayashi, M. Maeda, K. Yanagida, J. Appl. Phys., 61, (1987), 5102.

/3/ J.R. Sellars, M. Tribus, J.S. Klein, Trans. ASME, 78, (1956), 441.

14/ J.O. Hirschfelder, C.F. Curtiss, R.B. Bird, "Molecular Theory of Gases and Liquids", John Wiley \& Sons, (1954).

/5/ T. Inagaki, H. Komiyama, Kagaku Kougaku Ronbunshu, 16, (1989), 849.

/6/ L.H. Hong, H. Komiyama, J. Amer. Cer. Soc., submitted.

7/ K. Watanabe, H. Komiyama, J. Electrochem. Soc., 137, (1990), 1222.

18/ Y. Egashira, K. Ikuta, K. Watanabe, H. Komiyama, Proc. Ilth Int. Conf. CVD, p.418, (1990).

/9/ Y. Egashira, T. Sorita, S. Shiga, K. Ikuta, H. Komiyama, Proc. EURO-CVD 8, submitted. 